\title{
5 \\ ESPAÑA: INNOVACIÓN Y DIVERSIFICACIÓN EN TIEMPOS DE PANDEMIA
}

DOI: https://doi.org/10.7764/obitel.21.S.7

\begin{abstract}
Autores:
Charo Lacalle, (https://orcid.org/0000-0002-0024-6591)

Beatriz Gómez (https://orcid.org/0000-0002-0557-528X),

Mariluz Sánchez (https://orcid.org/0000-0002-0076-7522), Javier Mateos-Pérez (https://0000-0003-2056-8704)
\end{abstract}

Equipo:

Sara Narvaiza, Rosa Ferrer, Raquel Crisóstomo, Tatiana Hidalgo-Marí, Berta Trullàs, Daria Dergacheva, Jesús Segarra-Saavedra

\section{Introducción}

El estado de alarma y el confinamiento domiciliario en España, por efecto de la pandemia, han determinado el aumento espectacular del consumo televisivo en 2020, que también ha revertido en el notable incremento de los abonados a las plataformas VoD. Pese al parón en la producción de la primera ola y al sucesivo encarecimiento de los costes por efecto de las medidas anti-COVID-19, la ficción española ratifica su dinamismo en el elevado número de títulos ofrecidos a lo largo del año. La tendencia de las dos grandes cadenas privadas a programar sus estrenos en VoD es, sin duda, uno de los aspectos destacables. 


\section{El contexto audiovisual de España en 2020}

El índice anual de audiencia ponderado de las tres grandes cadenas generalistas obtiene un nuevo mínimo histórico $(35,8 \%,-0,1)$. La televisión de pago, por el contrario, consigue un nuevo récord $(8,4 \%,+0,4)$, superando a las autonómicas $(8,2 \%)$, que mantienen sus resultados de 2019. La situación de excepcionalidad aumenta el consumo televisivo, mientras que la inversión publicitaria experimenta un elevado descenso.

\subsection{La televisión abierta en España}

Las principales cadenas de televisión pública y privada se resienten por el incremento de la oferta de pago. A pesar de algunos incrementos significativos, como el de Nova $(+0,3)$, Trece $(+0,2)$ o BeMadTV $(+0,2)$, el índice acumulado de la oferta de las cadena temáticas (TDT) también se debilita $(28,7 \%,-0,4)$ como consecuencia de los resultados de FDF, Neox y las cadenas infantiles (Clan, Boing y Disney Channel), que alcanzan sus mínimos de los últimos 10 años.

\section{Cuadro1. Cadenas nacionales de televisión abierta en España}

\begin{tabular}{|c|c|c|c|c|}
\hline Titularidad & \multicolumn{2}{|l|}{ Públicas } & \multicolumn{2}{|c|}{ Privadas } \\
\hline \multirow{2}{*}{ Estatales } & Primer canal & $\begin{array}{l}\text { Segundo } \\
\text { canal }\end{array}$ & $\begin{array}{l}\text { Primer } \\
\text { canal }\end{array}$ & Segundos Canales \\
\hline & Lal & $\begin{array}{l}\mathrm{La} 2 \\
24 \mathrm{H} \\
\text { Clan } \\
\text { Teledeporte }\end{array}$ & $\begin{array}{l}\text { Antena3, } \\
\text { Cuatro, } \\
\text { LaSexta, } \\
\text { Tele5 }\end{array}$ & $\begin{array}{l}\text { Atreseries, BEMADtv, Boing, } \\
\text { Disney Channel, Divinity, } \\
\text { DKISS, DMax, El Toro TV, } \\
\text { Energy, FDF, Gol, Mega, Neox, } \\
\text { Nova, Paramount Network, Real } \\
\text { Madrid HD, Ten, Trece }\end{array}$ \\
\hline Autonómicas & $\begin{array}{l}\text { Á punt, Aragón } \\
\text { TV, CanalSur, } \\
\text { CMM, ETB1, } \\
\text { ETB2, C. } \\
\text { Extremadura, } \\
\text { IB3, } \\
\text { Telemadrid, } \\
\text { TPA, TV3, } \\
\text { TVCAN, TVG } \\
\end{array}$ & $\begin{array}{l}\text { 3/24, And-TV, } \\
\text { CSur-And, } \\
\text { Esport3, ETB3, } \\
\text { ETB4, Galicia } \\
\text { TV, LaOtra, } \\
\text { Super3/33, TPA2, } \\
\text { TV3CAT, TVG2 }\end{array}$ & \multicolumn{2}{|c|}{$\begin{array}{l}\text { 8Madrid, 8TV, BOM Cine, HitTV, La7, La8 } \\
\text { Mediterráneo, Fibracat TV }\end{array}$} \\
\hline \multicolumn{5}{|c|}{ TOTAL CADENAS $=59$} \\
\hline
\end{tabular}

Fuente: Obitel España 
Tras la declaración del Estado de alarma el 14 de marzo, se decretó un confinamiento de dos semanas para frenar la propagación del coronavirus, que tuvo un impacto inmediato en el consumo televisivo (lineal y diferido). Se revirtió la tendencia negativa de los últimos dos años con 18 minutos más que en 2019, que situaron el consumo en 240 minutos por persona y día en 2020 (un dato idéntico al de 2017). No obstante, cabe señalar que este año se han introducido dos cambios importantes en la medición de las audiencias: la inclusión de las segundas residencias en enero y la ampliación del número de audímetros (5.720 hogares en octubre).

Por noveno año consecutivo, Tele 5 ha sido la cadena más vista $(14,6 \%,-0,2)$, seguida por Antena3 $(11,8 \%,+0,1)$ y La1, que repite su mínimo histórico anual con el mismo índice del año pasado $(9,4 \%)$. LaSexta también ofrece un resultado idéntico al de 2019 (7\%), mientras que Cuatro se sitúa en un 5,4\% $(+0,1)$.

\section{Gráfico 1. Share por cadenas estatales}

\begin{tabular}{|l|c|}
\hline Cadena & \multicolumn{1}{l|}{ \% } \\
\hline Tele5 & 14,6 \\
\hline A3 & 11,8 \\
\hline La1 & 9,4 \\
\hline TDT pago & 8,4 \\
\hline Autonómicas & 8,2 \\
\hline LaSexta & 7,0 \\
\hline Cuatro & 5,4 \\
\hline La 2 & 2,8 \\
\hline TDT abierto & 28,7 \\
\hline Otras & 3,7 \\
\hline TOTAL & $\mathbf{1 0 0 , 0 0}$ \\
\hline
\end{tabular}

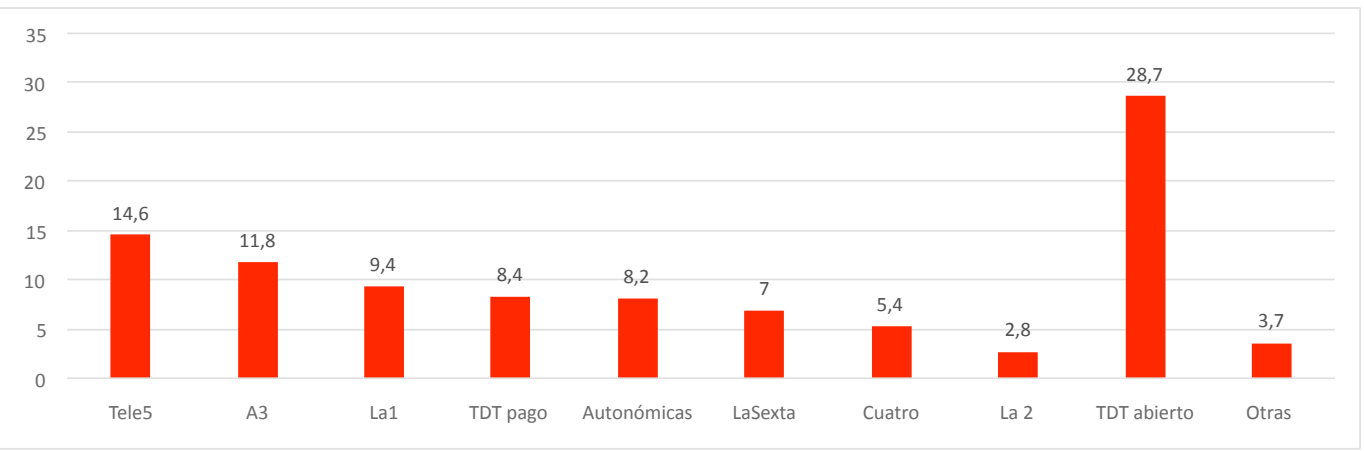

Fuente: Barlovento Comunicación/KantarMedia. 
Las cadenas autonómicas públicas $(8,2 \%)$, así como las privadas $(0,4 \%)$, mantienen los mismos registros de 2019; es decir, el mejor resultado desde 2014 para las primeras y el mínimo anual de la década para las segundas. TV3 $(14,6 \%)$ es, de nuevo, la cadena con mayor cuota de pantalla del conjunto y ratifica su liderazgo en Cataluña por undécimo año consecutivo. Le sigue ETB2 $(10 \%,+1,7)$, que desplaza así a TVG $(9,9 \%,+0,6)$ hasta el tercer lugar.

\section{Gráfico 1a. Share por cadenas autonómicas}

\begin{tabular}{|l|c|}
\hline Cadenas & \% \\
\hline TV3 & 14,6 \\
\hline ETB2 & 10,0 \\
\hline TVG & 9,9 \\
\hline AragónTV & 9,3 \\
\hline C. Sur & 7,5 \\
\hline TPA & 6,8 \\
\hline C. Extremadura & 6,2 \\
\hline TV CAN & 5,9 \\
\hline CMM & 5,6 \\
\hline Telemadrid & 5,4 \\
\hline IB3 & 4,7 \\
\hline LA 7TV & 4,0 \\
\hline À punt & 3,0 \\
\hline ETB1 & 1,7 \\
\hline 3//24 & 1,7 \\
\hline TPA2 & 1,1 \\
\hline La Otra & 0,9 \\
\hline TVG2 & 0,7 \\
\hline Super3/33 & 0,6 \\
\hline ETB4 & 0,6 \\
\hline TV3CAT & 0,4 \\
\hline And. TV & 0,4 \\
\hline Esport3 & 0,3 \\
\hline ETB3 & 0,3 \\
\hline Csur_And & 0,2 \\
\hline Galicia TV & 0,1 \\
\hline Privadas & 0,4 \\
\hline TOTAL & $\mathbf{1 0 0 , 0 0}$ \\
\hline & \\
\hline
\end{tabular}

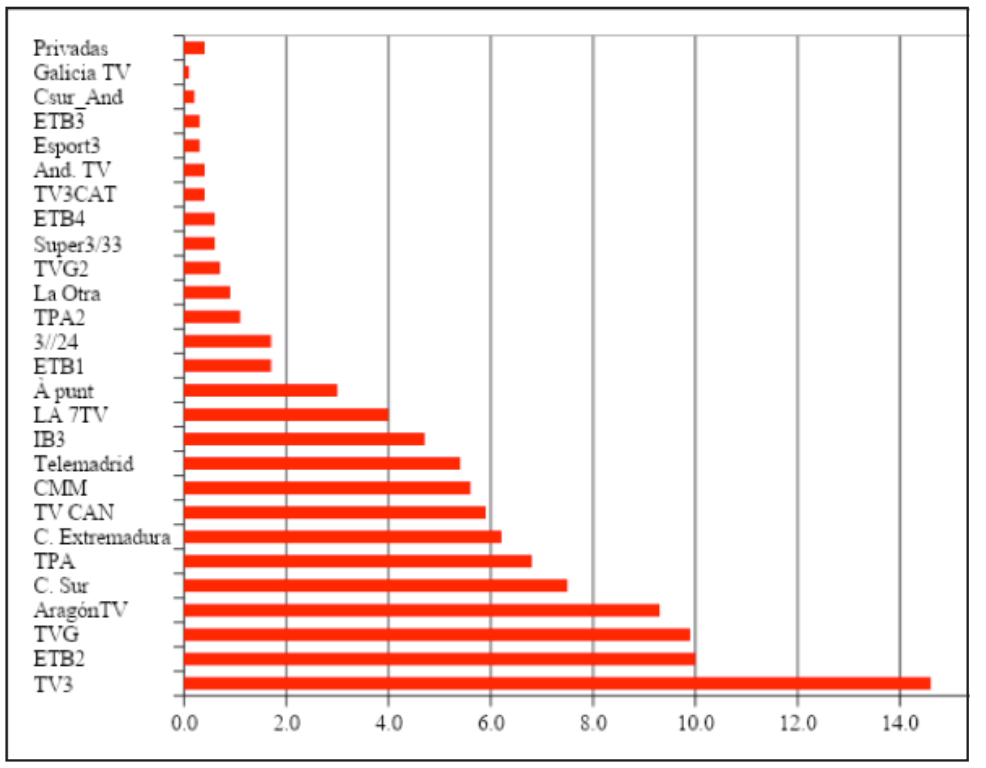

Fuente: Barlovento Comunicación/KantarMedia.

El liderazgo por grupos empresariales corresponde, un año más, a Mediaset $(28,4 \%,-0,5)$, seguido de Atresmedia $(26,3 \%,+0,1)$. Así, la cuota de audiencia de ambos líderes representa más de la mitad del total (54,8\%), aunque vuelven a perder cuatro décimas respecto a 
2019. RTVE suma $15,4 \%$ (-0,1 puntos); mientras la FORTA $(8,1 \%)$ repite resultado. Tanto Vocento (2,6\%) como Unidad Editorial (2,5\%) pierden tres décimas.

La ficción retrocede respecto a 2019, pero sigue siendo el género con mayor presencia en las cadenas $(42,3 \%,-0,4)$, seguido por el entretenimiento $(17,8 \%,+0,6)$, la cultura $(13,7 \%,+0,3)$, el deporte $(10,8 \%,-0,8)$ y la información $(9,8 \%,+0,7)$. A pesar de su liderazgo entre los géneros, ningún programa de ficción figura entre las 50 emisiones más vistas del año.

Gráfico 2. Géneros y horas transmitidos en la programación de TV

\begin{tabular}{|l|c|}
\hline Géneros & $\mathbf{\%}$ \\
\hline Ficción & 42,3 \\
\hline Entretenimiento & 17,8 \\
\hline Cultura & 13,7 \\
\hline Deporte & 10,8 \\
\hline Información & 9,8 \\
\hline Música & 2,7 \\
\hline Concursos & 2,1 \\
\hline Otros & 0,3 \\
\hline Religiosos & 0,2 \\
\hline TOTAL & $\mathbf{1 0 0 , 0 0}$ \\
\hline
\end{tabular}

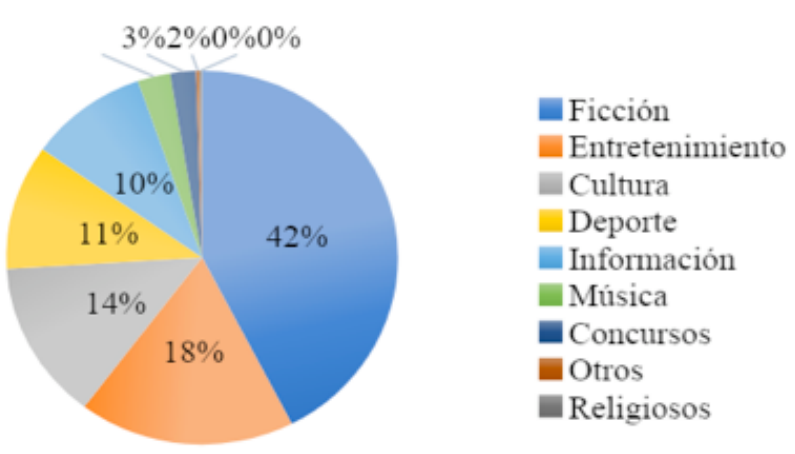

Fuente: Barlovento Comunicación/KantarMedia.

En términos económicos, 2020 no ha sido un buen año para los tres principales grupos audiovisuales. RTVE cerró el año con unas pérdidas en torno a los 50 millones de euros, es decir, casi el doble de las de 2019 (29,67 millones de euros), aunque ligeramente inferiores a las estimaciones del mes de julio (60 millones) ${ }^{1}$. En 2020, Mediaset

1 https://vertele.eldiario.es/noticias/RTVE-presupuesto-2021-1127-millones-subida-RosMaria-Mateo_0_2283971628.html 
obtuvo 178,7 millones de beneficios, un 15,6\% menos que en $2019^{2}$; y Atresmedia ganó 23,8 millones, lo que implica un descenso del 79,8\% respecto al año anterior ${ }^{3}$. La partida que más sufrió en ambos grupos fue la publicitaria (véase el apartado 1.4).

\subsection{La TV de pago y plataformas de VoD en España}

La TDT, presente en el 74\% de los hogares, mantiene su registro de 2019 y continua siendo el principal sistema de distribución de contenidos televisivos en España. No obstante, vuelve a liderar con su mínimo histórico como consecuencia del aumento de las suscripciones a la televisión de pago (IPTV, cable o satélite), que marca por el contrario un nuevo récord $(26,4 \%,+0,7)$ gracias al incremento del sistema IPTV $(16 \%+1,5)$.

En septiembre de 2020, 7.967.202 hogares estaban suscritos a alguna modalidad de televisión de pago ${ }^{4}, 15,5 \%$ más que el año pasado. En los primeros nueve meses del año, los ingresos de la televisión de pago ascendían a 1.582,65 millones de euros $(-5,4 \%)$, mientras que los de la televisión en abierto representaban 938,36 millones $(-22 \%){ }^{5}$

Los canales temáticos de pago promedian un $8,4 \%$ de audiencia (ver Gráfico 1), cuatro décimas más que en 2019, con lo que marcan un nuevo récord histórico. Entre las diez cadenas de pago más vistas figuran Fox España, responsable de la continuación de Vis a Vis (Vis a Vis. El Oasis); TNT, que en 2020 estrenó Vamos Juan, y \#0, que emite la amplísima oferta de ficción original de Movistar+.

2 https://files.mediaset.es/file/10002/2021/02/24/FY_20_SPANISH_CNMV_f7a7.pdff

3 https:/www.atresmediacorporacion.com/documents/2021/02/25/ACCF96A3-2088-

4208-8394-DD4B4DCEB6D7/atresmediaresultados_2020cnmv.pdf

$4 \mathrm{http} / / /$ data.cnmc.es/datagraph/jsp/inf_trim.jsp

$5 \mathrm{http}: / /$ data.cnmc.es/datagraph/jsp/inf_trim.jsp 
Cuadro 2. Cadenas de televisión de pago en España

\begin{tabular}{|l|}
\hline $\begin{array}{c}\text { Las } 10 \text { Cadenas de TV Pago más } \\
\text { vistas en } 2020\end{array}$ \\
\hline 1) Movistar Laliga (fútbol), 2) Fox \\
(ficción), 3) AXN (ficción), 4), \\
TNT (ficción), 5) Calle 13 \\
(ficción), 6) Canal Hollywood \\
(cine), 7) Comedy Central \\
(comedia), 8) Fox Life \\
(entretenimiento), 9) \#0 \\
(entretenimiento) y 10) Historia \\
(documentales) \\
\hline
\end{tabular}

Fuente: Barlovento Comunicación/KantarMedia

\section{Cuadro 3. El VoD en España}

\begin{tabular}{|l|c|}
\hline \multicolumn{1}{|c|}{$\begin{array}{c}\text { Principales plataformas } \\
\text { de VoD activas en } \mathbf{2 0 2 0}^{\mathbf{6}}\end{array}$} & Total \\
\hline $\begin{array}{l}\text { Netflix, Amazon Prime Video, HBO, } \\
\text { Disney+, Apple TV, Movistar+ y Movistar+ }\end{array}$ & 28 \\
Lite (Telefónica), Vodafone TV (Vodafone), \\
Orange TV (Orange), Starzplay, Rakuten TV, \\
Pluto TV, fuboTV, Sky, Filmin, Cineclick, \\
FlixOlé, DAZN, Acorn TV, LovesTV, \\
RTVEalacarta.es (TVE), Atresplayer \\
Premium (Atresmedia), Mitele Plus \\
(Mediaset), Mubi, IQiyi, Crunchyroll, Quibi, \\
Planet Horror
\end{tabular}

Fuente: Obitel España

6 No se incluyen ni las plataformas vinculadas a las cadenas de ámbito autonómico o local ni los canales de YouTube. 


\subsection{Productoras independientes de ficción televisiva}

Desde hace un par de años, los profundos cambios en el panorama audiovisual español han ido convirtiendo a los competidores en socios de negocio. Entre otras alianzas de 2020, Atresmedia y Telefónica se unieron en junio para crear Buendía Estudios, con el objetivo de producir a nivel internacional. También se confirmaba el acuerdo de colaboración entre Warner Bros. y Alea Media, la productora de Aitor Gabilondo, para desarrollar dos series de televisión, y se recogían los primeros frutos de la alianza estratégica entre, por un lado Mediapro y Orange (la serie Caminantes) y, por otro lado, Mediapro con Hulu Japón y HBO Asia (la serie The Head).

\subsection{Fuentes de financiamiento del sector audiovisual}

La inversión publicitaria ha continuado su tendencia negativa y, por segundo año consecutivo, la televisión ha dejado de ser líder entre los medios, posición que ahora ocupa la categoría Digital. La inversión publicitaria en televisiva decreció un 18,4\% respecto al mismo período del año anterior, con un total de 1.067,6 millones de euros. La inversión publicitaria del grupo de televisiones nacionales en abierto retrocedió un 25,2\% (953,1 millones de euros), situando su cuota de mercado en el 89,3\% (-0.9); mientras que entre las televisiones autonómicas el descenso representaba un 19,8\% (49,2 millones de euros), con una cuota del $4,6 \%(+0,3)$. Los canales de pago presentaban un descenso del 14,3\% (64 millones), con una cuota de mercado del $6 \%(+0,7)^{7}$. El gobierno aprobó en abril una partida de 15 millones en ayudas para las televisiones privadas con el objetivo de paliar la drástica caída de la inversión publicitaria.

7 https://www.infoadex.es/home/wp-content/uploads/2021/02/NP-Estudio-InfoAdex-dela-Inversión-Publicitaria-en-España-2021.pdf 
Según datos de Infoadex, los ingresos por publicidad de Mediaset registraron 709 millones de euros, un 18,4\% menos respecto al año anterior; mientras que Atresmedia ingresó 656,1 millones, un descenso del 19,5\% respecto a 2019. Con estos resultados, Mediaset obtuvo una cuota de mercado del 43,2\% y Atresmedia, del 40\%, lo que significa que los dos líderes de la televisión abierta en España mantuvieron su hegemonía en los ingresos publicitarios: el 83,2\% del total de la inversión en televisión. ${ }^{8}$

\subsection{Políticas de comunicación}

En noviembre de 2020, el Ejecutivo presentó el anteproyecto de la nueva Ley General de Comunicación Audiovisual, más conocida como "tasa Netflix", que obliga a los "prestadores del servicio de comunicación audiovisual televisivo a petición", es decir, a las nuevas plataformas de vídeo y el resto de nuevos operadores, a destinar un $5 \%$ de los ingresos generados en España a la financiación de obra audiovisual europea o a la contribución al Fondo de Protección de la Cinematografía del Instituto de la Cinematografía y de las artes audiovisuales (ICAA). Sin embargo, y en contra de lo que se esperaba, esta nueva legislación no cubre la financiación de RTVE, a la que en cambio contribuyen las cadenas de televisión privadas y los operadores de telecomunicaciones. Se trata, por tanto, de un agravio comparativo para el resto de operadores, que la Unión de Televisiones Comerciales en Abierto (UTECA) ya ha denunciado.

\subsection{Infraestructura de conectividad digital y móvil}

En junio, España comunicaba a la Unión Europea que, a consecuencia de la situación excepcional generada por el COVID-19, era

8 http://www.geca.es/geca/informes/20201230--E1\%20balance $\% 20 \mathrm{del} \% 20$ a\%C3\%B10\%20-\%202020.pdf 
imposible culminar el Segundo Dividendo Digital antes del día 30 del mismo mes; es decir, el proceso por el que se liberan las frecuencias de la banda de los $700 \mathrm{MHz}$, ahora ocupadas por canales de la TDT, con el fin de ser utilizadas para el despliegue de las redes 5G. Así pues, se estableció el 31 de octubre como nueva fecha para la finalización. Con el objetivo de sufragar los cambios necesarios en los equipos transmisores, el Consejo de Ministros aprobó en julio subvenciones por un importe máximo de 10 millones de euros a las televisiones privadas. Ese mismo mes, RTVE lanzaba las versiones restauradas en $4 \mathrm{~K}$ de $E l$ Quijote y La Regenta, las primeras dos obras del Fondo Documental de la corporación que han sido objeto de remasterización en ultra alta definición.

\section{Análisis del año: la ficción de estreno nacional e iberoamericana}

El número de estrenos de ficción propia en 2020 asciende a 75 títulos (13 estatales, 18 autonómicos y $43 \mathrm{VoD}$ ), uno más que en el año pasado. Se trata de un dato realmente remarcable en tiempos de pandemia, debido principalmente a la extraordinaria aportación de las plataformas de pago, que ratifica el dinamismo de la ficción española. El empuje del VoD ha introducido cambios radicales en la programación de las dos grandes cadenas privadas estatales, que han optado por estrenar algunas de sus ficciones en la modalidad de streaming.

Antena3 ha ofrecido en abierto únicamente los seriales $\mathrm{El} \mathrm{Se}$ creto del Puente Viejo y Amar Es para Siempre y ha trasladado el resto de sus ficciones a Atresplayer, una tendencia inaugurada el año pasado con un thriller disponible actualmente en Netflix (El Nudo). Tele5 ha estrenado en abierto dos comedias, que sucesivamente se han incorporado al catálogo de Amazon Prime Video, y seis series en VoD (cuatro en esta última plataforma, una en HBO y una en Netflix). La1 es la única de las tres grandes cadenas estatales que continúa estrenando toda su ficción en abierto y ofreciéndola sucesivamente en su propia plataforma gratuita. 
Tabla 1. Ficciones exhibidas en 2020. Cadenas estatales

\begin{tabular}{|c|c|}
\hline $\begin{array}{l}\text { TÍTULOS INÉDITOS NACIONALES } \\
\text { - No } 13 \\
\text { La1 -9 títulos nacionales } \\
\text { 1. Cuéntame Cómo Pasó (serie) } \\
\text { 2. HIT (serie) } \\
\text { 3. Diarios de la Cuarentena (serie) } \\
\text { 4. El Ministerio del Tiempo (serie) } \\
\text { 5. Néboa (serie) } \\
\text { 6. Servir y Proteger (serial) } \\
\text { 7. Historias de Alcafrán (serie) } \\
\text { 8. Mercado Central (serial) } \\
\text { 9. Acacias } 38 \text { (serial) } \\
\text { Antena3 - } 2 \text { títulos nacionales } \\
\text { 10. El Secreto del Puente Viejo (serial) } \\
\text { 11. Amar Es para Siempre (serial) } \\
\text { Tele5-2 títulos nacionales } \\
\text { 12. Lejos de Ti (serie) } \\
\text { 13. El Pueblo (serie) }\end{array}$ & $\begin{array}{l}\text { TÍTULOS REPOSICIONES- } \mathbf{N}^{\mathbf{0}} \mathbf{1 3} \\
\text { La1 - } \mathbf{5} \text { títulos nacionales } \\
\text { 1. Olmos y Robles (serie) } \\
\text { 2. El Final del Camino (serie) } \\
\text { 3. Fugitiva (serie) } \\
\text { 4. El Caso. Crónica de Sucesos (serie) } \\
\text { 5. Hospital Valle Norte (serie) } \\
\text { Tele5 - } 3 \text { títulos nacionales } \\
\text { 6. La que Se Avecina (serie) } \\
\text { 7. Escenas de Matrimonio (sketches) } \\
\text { 8. Lo que Escondían Tus Ojos (miniserie) } \\
\text { Cuatro - } 1 \text { título nacional } \\
\text { 9. Gym Toni (serie) } \\
\text { Divinity - } 4 \text { títulos nacionales } \\
\text { 10. Hospital Central (serie) } \\
\text { 11. MIR (serie) } \\
\text { 12. Al Salir de Clase (serie) } \\
\text { 13. Yo Soy Bea (serial) } \\
\text { TOTAL DE TíTULOS INÉDITOS } \\
\text { NACIONALES:13 }\end{array}$ \\
\hline
\end{tabular}

Fuente: Obitel España.

La amplia oferta de las plataformas VoD repercute también en la disminución de las redifusiones, una constante desde la consolidación de la TDT en 2011, aunque las estrategias al respecto de las dos grandes cadenas privadas son divergentes. Así, mientras que Antena3 se muestra reticente a emitir en abierto los estrenos de Atresplayer, Tele5 incorporó Madres, Patria, Perdida y Veneno a su propia parrilla, tras su debut en Amazon Prime Video.

Los 18 títulos de las cadenas autonómicas representan sólo uno menos que el año pasado, un dato coherente con la estabilidad en términos de audiencia de este grupo de canales, que también han remontado satisfactoriamente el primer año de la pandemia. La aportación de la cadena catalana TV3 y la gallega TVG sobresalen un año más respecto del conjunto, con cinco títulos cada una. Aragón TV de- 
buta en la producción de ficción con un drama, mientras que ETB1 aporta tres miniseries y el final de la cuarta y la quinta temporadas de su exitosa serie juvenil Go!azen, en emisión desde 2009.

Tabla 1a. Ficciones exhibidas en 2020. Cadenas autonómicas

\begin{tabular}{|c|c|}
\hline $\begin{array}{l}\text { TÍTULOS INÉDITOS } \\
\text { AUTONÓMICOS - N } 18 \\
\text { TV3 - No } \mathbf{4} \\
\text { 1. Com Si Fos Ahir (serial) } \\
\text { 2. Jo També Em Quedo a Casa (serie) } \\
\text { 3. La Fossa (miniserie) } \\
\text { 4. Les de L’Hoqei (serie) } \\
\text { 5. Drama (serie) } \\
\text { TVG - No } \mathbf{3} \\
\text { 6. A Estiba (serie) } \\
\text { 7. Do Dereito e do Revés (formato) } \\
\text { 8. Os Mariachi (formato) } \\
\text { 9. A Lei de Santos (serie) } \\
\text { 10. Serramoura (serie) } \\
\text { ETB1 - No } 4 \\
\text { 11. Alardea (miniserie) } \\
\text { 12. Go!azen (miniserie) } \\
\text { 13. Hondar Ahoak (miniserie) } \\
\text { 14. Altsasu (miniserie) } \\
\text { IB3 - No } 2 \\
\text { 15. Mai Neva a Ciutat (serie) } \\
\text { 16. Pep (serie) } \\
\text { Aragón TV } \\
\text { 17. El Último Show (serie) } \\
\text { COPRODUCCIONES - No } \mathbf{1} \\
\text { TVG - No títulos } \\
\text { 18. Auga Seca (serie) (España y Portugal) }\end{array}$ & $\begin{array}{l}\text { TÍTULOS REPOSICIONES- } \mathbf{N}^{\mathbf{0}} \mathbf{1 6} \\
\text { Aragon TV } \\
\text { 1. Matalobos (serie) } \\
\text { 2. La Sala (serie) } \\
\text { 3. Merlin (serie) } \\
\text { À Punt } \\
\text { 4. Açó Es Un Destarifo (serie) } \\
\text { 5. Unió Musical Da Capo (serie) } \\
\text { 6. Maniàtics (serie) } \\
\text { 7. Socarrats (serie) } \\
\text { 8. Les de L'Hoqei (serie) } \\
\text { 9. Nit i Dia (serie) } \\
\text { 10. La Sala (serie) } \\
\text { CMT } \\
\text { 11. El Faro (serie) } \\
\text { 12. La Sala (serie) } \\
\text { 13. La Esclava Blanca (serie) } \\
\text { RTVC } \\
\text { 14. El Último Show (serie) } \\
\text { Telemadrid } \\
\text { 15. La Sala (serie) } \\
\text { TOTAL DE TÍTULOS INÉDITOS } \\
\text { AUTONÓMICOS: 17 } \\
\text { TOTAL DE COPRODUCCIONES OBITEL: } 1\end{array}$ \\
\hline
\end{tabular}

Fuente: Obitel España.

El descenso de los estrenos de la ficción estatal en las cadenas en abierto queda compensado en parte con el incremento del número de títulos iberoamericanos (ocho frente a los tres de 2019). La longitud de las telenovelas latinoamericanas reduce, a su vez, la diferencia de horas respecto del año anterior (1.380 horas y 35 minutos en 2020 
y 1.424 horas en 2019), al tiempo que determina el ligero incremento del número de capítulos/episodios (1.564 en 2020 y 1.424 en 2019).

Tabla 2. La Ficción de Estreno en 2020: España

\begin{tabular}{|c|c|c|c|c|c|c|}
\hline País & Títulos & $\%$ & Capítulos/Episodios & $\%$ & Horas & $\%$ \\
\hline NACIONAL (total) & 13 & 61,9 & 1.145 & 73,2 & 1.030:10:00 & 74,6 \\
\hline PAÍSES OBITEL (total) & 8 & 38,1 & 419 & 26,8 & 350:25:00 & 25,4 \\
\hline Argentina & 0 & 0,0 & 0 & 0,0 & 0:00:00 & 0,0 \\
\hline Brasil & 1 & 4,8 & 31 & 2,0 & $23: 15: 00$ & 1,7 \\
\hline Chile & 0 & 0,0 & 0 & 0,0 & 0:00:00 & 0,0 \\
\hline Colombia & 1 & 4,8 & 42 & 2,7 & 31:30:00 & 2,3 \\
\hline Ecuador & 0 & 0,0 & 0 & 0,0 & 0:00:00 & 0,0 \\
\hline España & 13 & 61,9 & 1.145 & 73,2 & 1.030:10:00 & 74,6 \\
\hline EEUU (producción hispánica) & 1 & 4,8 & 105 & 6,7 & 78:45:00 & 5,7 \\
\hline México & 4 & 19,0 & 230 & 14,7 & 205:55:00 & 14,9 \\
\hline Perú & 0 & 0,0 & 0 & 0,0 & 0:00:00 & 0,0 \\
\hline Portugal & 0 & 0,0 & 0 & 0,0 & 0:00:00 & 0,0 \\
\hline Uruguay & 0 & 0,0 & 0 & 0,0 & 0:00:00 & 0,0 \\
\hline Venezuela & 0 & 0,0 & 0 & 0,0 & 0:00:00 & 0,0 \\
\hline COPRODUCIONES (total) & 1 & 100,0 & 11 & 100,0 & 11:00:00 & 100,0 \\
\hline Coproducciones españolas & 0 & 0,0 & 0 & 0,0 & 0:00:00 & 0,0 \\
\hline Coproducciones entre países Obitel & 1 & 100,0 & 11 & 100,0 & 11:00:00 & 100,0 \\
\hline TOTAL GENERAL & 21 & 100,0 & 1.564 & 100,0 & 1.380:35:00 & 100,0 \\
\hline
\end{tabular}

Fuente: Obitel España.

La diferencia entre el número de horas del total español (estatal y autonómico) respecto de 2019 es aún más reducida (1.567 horas y 35 minutos en 2020 frente a 1.681 horas y 10 minutos en 2019), pese a que este año se han estrenado siete títulos menos que en el pasado (39 y 46 respectivamente). Disminuye, en cambio, el número de capítulos/episodios (1.817 en 2020 y 1.940 en 2019). 
Tabla 2a. La Ficción de Estreno en 2020: España (estatal y autonómica)

\begin{tabular}{|l|r|r|r|r|r|r|}
\hline \multicolumn{1}{|c|}{ País } & Títulos & \multicolumn{1}{c|}{$\%$} & Capítulos/Episodios & \multicolumn{1}{c|}{$\%$} & \multicolumn{1}{c|}{ Horas } & \multicolumn{1}{c|}{} \\
\hline NACIONAL (total) & $\mathbf{3 1}$ & $\mathbf{7 9 , 5}$ & $\mathbf{1 . 3 9 8}$ & $\mathbf{7 6 , 9}$ & $\mathbf{1 . 2 1 7 : 1 0 : 0 0}$ & $\mathbf{7 7 , 6}$ \\
\hline PAíSES OBITEL (total) & $\mathbf{8}$ & $\mathbf{2 0 , 5}$ & $\mathbf{4 1 9}$ & $\mathbf{2 3 , 1}$ & $\mathbf{3 5 0 : 2 5 : 0 0}$ & $\mathbf{2 2 , 4}$ \\
\hline Argentina & 0 & 0,0 & 0 & 0,0 & $0: 00: 00$ & 0,0 \\
\hline Brasil & 1 & 2,6 & 31 & 1,7 & $23: 15: 00$ & 1,5 \\
\hline Chile & 0 & 0,0 & 0 & 0,0 & $0: 00: 00$ & 0,0 \\
\hline Colombia & 1 & 2,6 & 42 & 2,3 & $31: 30: 00$ & 2,0 \\
\hline Ecuador & 0 & 0,0 & 0 & 0,0 & $0: 00: 00$ & 0,0 \\
\hline España & $\mathbf{3 0}$ & $\mathbf{7 6 , 9}$ & $\mathbf{1 . 3 9 2}$ & $\mathbf{7 6 , 6}$ & $\mathbf{1 2 1 2 : 1 0 : 0 0}$ & $\mathbf{7 7 , 3}$ \\
\hline EEUU (producción hispánica) & 1 & 2,6 & 105 & 5,8 & $78: 45: 00$ & 5,0 \\
\hline México & 4 & 10,3 & 230 & 12,7 & $205: 55: 00$ & 13,1 \\
\hline Perú & 0 & 0,0 & 0 & 0,0 & $0: 00: 00$ & 0,0 \\
\hline Portugal & 0 & 0,0 & 0 & 0,0 & $0: 00: 00$ & 0,0 \\
\hline Uruguay & 0 & 0,0 & 0 & 0,0 & $0: 00: 00$ & 0,0 \\
\hline Venezuela & 0 & 0,0 & 0 & 0,0 & $0: 00: 00$ & 0,0 \\
\hline COPRODUCIONES (total) & $\mathbf{2}$ & $\mathbf{1 0 0 , 0}$ & $\mathbf{1 8}$ & $\mathbf{1 0 0 , 0}$ & $\mathbf{1 6 : 0 0 : 0 0}$ & $\mathbf{1 0 0 , 0}$ \\
\hline Coproducciones españolas & 1 & 50,0 & 6 & 33,3 & $5: 00: 00$ & 31,3 \\
\hline Coproducciones entre países Obitel & 1 & 50,0 & 11 & 61,1 & $11: 00: 00$ & 68,8 \\
\hline TOTAL GENERAL & $\mathbf{3 9}$ & $\mathbf{1 0 0 , 0}$ & $\mathbf{1 . 8 1 7}$ & $\mathbf{1 0 0 , 0}$ & $\mathbf{1 . 5 6 7 : 3 5 : 0 0}$ & $\mathbf{1 0 0 , 0}$ \\
\hline
\end{tabular}

Fuente: Obitel España.

Los cinco seriales españoles emitidos en las cadenas estatales representan un $38,5 \%$ del total de formatos y 969 horas de emisión, a las que cabe sumar las 350 horas y 25 minutos de las ocho telenovelas de estreno (100\% del total iberoamericano). Se trata de unos datos cuya significatividad se incrementa si se tiene en cuenta que 2020 es el año en que el formato serial ha regresado al prime time estatal, tras casi 30 años de ausencia, aunque en esta ocasión lo haya hecho de la mano de las producciones turcas Mujer y Mi Hija. Las dos emisiones de esta última telenovela, estrenada en diciembre, la han convertido en el primer programa de ficción que se introduce entre los más vistos del año (en la novena posición del ranking anual). ${ }^{9}$

9 http://www.geca.es/geca/informes/20201230--E1\%20balance $\% 20$ de $1 \% 20$ a\%C3\%B10\%20-\%202020.pdf 
Tabla 3. Formatos de la ficción nacional e iberoamericana

\begin{tabular}{|c|c|c|c|c|c|c|c|c|c|c|c|c|}
\hline \multirow{2}{*}{ Formato } & \multicolumn{6}{|c|}{ Nacionales } & \multicolumn{6}{|c|}{ Ibero-americanos } \\
\hline & Títulos & $\%$ & $\mathbf{C} / \mathbf{E}$ & $\%$ & $\mathbf{H}$ & $\%$ & Títulos & $\%$ & $\mathbf{C} / \mathbf{E}$ & $\%$ & $\mathbf{H}$ & $\%$ \\
\hline $\begin{array}{l}\text { Serial/ } \\
\text { Telenovela }\end{array}$ & 5 & 38,5 & 66 & 5,8 & 969:00:00 & 94,1 & 8 & 100,0 & 419 & 100,0 & $350: 25: 00$ & 100,0 \\
\hline Serie & 8 & 61,5 & 1079 & 94,2 & 61:10:00 & 5,9 & 0 & 0,0 & 0 & 0,0 & 0 & 0,0 \\
\hline Miniserie & 0 & 0,0 & 0 & 0,0 & 0:00:00 & 0,0 & 0 & 0,0 & 0 & 0,0 & 0 & 0,0 \\
\hline Telefilme & 0 & 0,0 & 0 & 0,0 & 0:00:00 & 0,0 & 0 & 0,0 & 0 & 0,0 & 0 & 0,0 \\
\hline Unitario & 0 & 0,0 & 0 & 0,0 & 0:00:00 & 0,0 & 0 & 0,0 & 0 & 0,0 & 0 & 0,0 \\
\hline Docudrama & 0 & 0,0 & 0 & 0,0 & 0:00:00 & 0,0 & 0 & 0,0 & 0 & 0,0 & 0 & 0,0 \\
\hline Otros & 0 & 0,0 & 0 & 0,0 & 0:00:00 & 0,0 & 0 & 0,0 & 0 & 0,0 & 0 & 0,0 \\
\hline
\end{tabular}

Fuente: Obitel España.

La diversificación de los formatos de estreno en 2020 es mayor en el total español respecto de la ficción estatal, pues las cadenas autonómicas aportan en esta ocasión cuatro miniseries (tres de las cuales de ETB1 y una de TV3), aunque su presencia en antena únicamente representa el 1\% del total. El tiempo de emisión dedicado a las series autóctonas se incrementa en cambio de manera exponencial, con 169 horas de emisión (13,9\% frente al 5,9\% de la ficción estatal).

Tabla 3a. Formatos de la ficción nacional e iberoamericana

\begin{tabular}{|l|c|c|c|c|c|c|}
\hline \multirow{2}{*}{ Formato } & \multicolumn{7}{|c|}{ Nacionales y Autonómicas } \\
\cline { 2 - 8 } & Tít. & $\mathbf{\%}$ & $\mathbf{C} / \mathbf{E}$ & $\mathbf{\%}$ & $\mathbf{H}$ & \% \\
\hline Serial/ Telenovela & 7 & 22,6 & 178 & 12,7 & $1.035: 50: 00$ & 85,1 \\
\hline Serie & 20 & 64,5 & 1.204 & 86,1 & $169: 00: 00$ & 13,9 \\
\hline Miniserie & 4 & 12,9 & 16 & 1,1 & $12: 20: 00$ & 1,0 \\
\hline Telefilme & 0 & 0,0 & 0 & 0,0 & $0: 00: 00$ & 0,0 \\
\hline Unitario & 0 & 0,0 & 0 & 0,0 & $0: 00: 00$ & 0,0 \\
\hline Docudrama & 0 & 0,0 & 0 & 0,0 & $0: 00: 00$ & 0,0 \\
\hline Total & $\mathbf{3 1}$ & $\mathbf{1 0 0 , 0}$ & $\mathbf{1 . 3 9 8}$ & $\mathbf{1 0 0 , 0}$ & $\mathbf{1 . 2 1 7 : 1 0 : 0 0}$ & $\mathbf{1 0 0 , 0}$ \\
\hline
\end{tabular}




\begin{tabular}{|l|c|c|c|c|c|c|}
\hline \multirow{2}{*}{ Formato } & \multicolumn{7}{|c|}{ Ibero-americanos } \\
\cline { 2 - 8 } & Tít. & $\mathbf{\%}$ & $\mathbf{C} / \mathbf{E}$ & $\mathbf{\%}$ & $\mathbf{H}$ & \% \\
\hline Serial/ Telenovela & 8 & 100,0 & 419 & 100,0 & $350: 25: 00$ & 100,0 \\
\hline Serie & 0 & 0,0 & 0 & 0,0 & $0: 00: 00$ & 0,0 \\
\hline Miniserie & 0 & 0,0 & 0 & 0,0 & $0: 00: 00$ & 0,0 \\
\hline Telefilme & 0 & 0,0 & 0 & 0,0 & $0: 00: 00$ & 0,0 \\
\hline Unitario & 0 & 0,0 & 0 & 0,0 & $0: 00: 00$ & 0,0 \\
\hline Docudrama & 0 & 0,0 & 0 & 0,0 & $0: 00: 00$ & 0,0 \\
\hline Total & $\mathbf{8}$ & $\mathbf{1 0 0 , 0}$ & $\mathbf{4 1 9}$ & $\mathbf{1 0 0 , 0}$ & $\mathbf{3 5 0 : 2 5 : 0 0}$ & $\mathbf{1 0 0 , 0}$ \\
\hline
\end{tabular}

Fuente: Obitel España.

El estreno de la mayor parte de las ficciones de Antena3 y Tele5 en la modalidad de VoD resalta la aportación de La1 al top 10 de 2020, con seis títulos, a la vez que evidencia la acertada apuesta de Tele 5 de estrenar en abierto sus comedias El Pueblo (2.199.000 espectadores y $16,8 \%$ de share) y Lejos de Ti (1.716.000 espectadores y $11,8 \%$ de share), situadas respectivamente en el primer puesto y en el tercero de la clasificación anual. El Pueblo, una creación de la misma productora que la popular La Que Se Avecina (Contubernio), narra la compleja convivencia entre un grupo de urbanitas recientemente asentados en la provincia de Soria y los habitantes locales. Lejos de Ti es una comedia con toques de fantasía y enredo coproducida por Mediaset España y Cross Production, sobre el enamoramiento de una joven sevillana y un romano que se conocen en un aeropuerto. La longeva serie de La1, Cuéntame Cómo Pasó (2.189.000 espectadores y 14,4\% de share), ambientada entre 1990 y 1991, resiste el paso del tiempo y sitúa su vigésima temporada en la segunda posición del ranking anual, con 4,4 puntos de share menos que en 2019, que también le vale el puesto número 24 de los programas más vistos del año. ${ }^{10}$ 
El reducido número de estrenos en abierto sitúa tres seriales en el ranking anual por primera vez. Las dos únicas ficciones de estreno ofrecidas por Antena3, Amar Es para Siempre (1.253.000 espectadores y $10,6 \%$ de share) y el tramo final de El Secreto del Puente Viejo (1.065.000 espectadores y 1,4\%), que se despedía en mayo tras nueve años en antena, ocupan respectivamente la sexta y la novena posición. Cierra la clasificación del top ten anual el policíaco de periodicidad diaria Servir y Proteger.

El relieve de los personajes femeninos de Néboa, el retorno de las teen series al prime time estatal (HIT), los estereotipos sobre contrastes de El Pueblo y la reflexión sobre el presente desde el pasado de los seriales, son aspectos destacables de los estrenos en abierto de la ficción estatal.

Tabla 4. Los diez títulos estatales más vistos de la ficción estatal

\begin{tabular}{|r|l|l|l|c|c|c|c|c|c|}
\hline \multicolumn{2}{|c|}{ Título } & $\begin{array}{l}\text { Origen } \\
\text { idea } \\
\text { original } \\
\text { o guión }\end{array}$ & Canal & $\begin{array}{c}\text { Formato/ } \\
\text { género }\end{array}$ & $\begin{array}{c}\text { Cap/ } \\
\text { ep }\end{array}$ & $\begin{array}{c}\text { Franja } \\
\text { horaria }\end{array}$ & Miles & Rating & Share \\
\hline 1 & El Pueblo & España & Tele5 & Serie / Comedia & 8 & Prime time & 2.199 .215 & 2,5 & 16,3 \\
\hline 2 & $\begin{array}{l}\text { Cuéntame } \\
\text { Cómo Pasó }\end{array}$ & España & La1 & $\begin{array}{c}\text { Serie / } \\
\text { Dramedy }\end{array}$ & 12 & Prime time & 2.189 .167 & 4,6 & 14,4 \\
\hline 3 & $\begin{array}{l}\text { España- } \\
\text { Lejos de Ti }\end{array}$ & Italia & Tele5 & Serie/ Comedia & 7 & Prime time & 1.716 .143 & 3,6 & 11,8 \\
\hline 5 & HIT & España & La1 & Serie / Drama & 10 & Prime time & 1.489 .800 & 3,1 & 9,1 \\
\hline 5 & $\begin{array}{l}\text { Diarios de la } \\
\text { Cuarentena }\end{array}$ & España & La1 & Serie / Comedia & 8 & Prime time & 1.315 .000 & 2,8 & 6,9 \\
\hline 6 & $\begin{array}{l}\text { El Ministerio } \\
\text { del Tiempo }\end{array}$ & España & La1 & Serie / Drama & 8 & Prime time & 1.298 .250 & 2,7 & 8,0 \\
\hline 7 & $\begin{array}{l}\text { Amar Es } \\
\text { paraSiempre }\end{array}$ & España & Antena3 & Serial / Drama & 251 & Tarde & 1.253 .239 & 2,6 & 10,6 \\
\hline 8 & Néboa & España & La1 & Serie / Thriller & 8 & Prime time & 1.234 .750 & 2,6 & 8,4 \\
\hline 9 & $\begin{array}{l}\text { El Secreto de } \\
\text { Puente Viejo }\end{array}$ & España & Antena3 & Serial / Drama & 86 & Tarde & 1.065 .423 & 2,3 & 9,4 \\
\hline 10 & $\begin{array}{l}\text { Serviry } \\
\text { Proteger }\end{array}$ & España & La1 & $\begin{array}{c}\text { Serial/ } \\
\text { Policiaco }\end{array}$ & 253 & Tarde & 995.569 & 2,1 & 8,9 \\
\hline
\end{tabular}

Fuente: Obitel España. 
En el ámbito autonómico, los estrenos de TV3 y TVG completan, una vez más, un ranking en el que este año se introduce la primera aportación de Aragón TV a la ficción autonómica: El Último Show. Se trata de un drama protagonizado por el célebre cómico aragonés "Marianico el Corto" (Miguel Ángel Tirado), que mezcla su vida y su personaje en una nostálgica rememoración del pasado bajo la dirección de Álex Rodrigo, codirector y coescritor de grandes éxitos como Vis a Vis (Antena3 y Fox, 2015-2019), La Casa de Papel (Antena3 y Netflix, 2017-) y El Embarcadero (Movistar+, 2019-20), entre otros.

La segunda temporada de Les de I'Hoqei (357.000 espectadores y $13,5 \%$ de share) encabeza la clasificación anual, tras aumentar su audiencia de manera espectacular respecto de la primera entrega en un año de descensos generalizados. Drama muestra que el interés de las cadenas estatales y de las plataformas VoD por las teen series se extiende también a la ficción autonómica.

El top 10 de 2020 incluye cuatro thrillers de TVG, un género tan popular en Galicia que ha llevado a la crítica a hablar del "boom del gallego noir" para acomunar un conjunto de producciones caracterizadas por la complejidad de los personajes, el ambiente de misterio y el protagonismo del espacio representado en los relatos, entre las que también figuran Néboa (La1) y El Desorden Que Dejas (Netflix). El título que encabeza la clasificación de la cadena gallega ( $A$ Ley de Santos) es un spin off del exitoso Serramoura, que concluía su trayectoria tras siete años en emisión. 
Tabla 4a. Formatos de la ficción nacional e iberoamericana

\begin{tabular}{|c|c|c|c|c|c|c|c|c|c|}
\hline & Título & $\begin{array}{c}\text { Origen } \\
\text { idea } \\
\text { original } \\
\text { o guión }\end{array}$ & Canal & Formato/género & Cap/ep & $\begin{array}{r}\text { Franja } \\
\text { horaria }\end{array}$ & Miles & Rating & Share \\
\hline 1 & \begin{tabular}{|l} 
Les de \\
l'Hoquei
\end{tabular} & España & TV3 & Serial / Drama & 13 & $\begin{array}{l}\text { Prime } \\
\text { time }\end{array}$ & 357.000 & 4,9 & 13,5 \\
\hline 2 & $\begin{array}{l}\text { Jo També } \\
\text { Em Quedo a } \\
\text { Casa } \\
\end{array}$ & España & TV3 & Serie / Dramedy & 20 & Tarde & 293.000 & 4,0 & 13,9 \\
\hline 3 & Drama & España & TV3 & Serie / Comedia & 6 & $\begin{array}{l}\text { Prime } \\
\text { time }\end{array}$ & 280.000 & 3,8 & 11,5 \\
\hline 4 & \begin{tabular}{|l} 
Com Si Fos \\
Ahir \\
\end{tabular} & España & TV3 & Serial / Drama & 112 & Tarde & 258.000 & 0,7 & 16,30 \\
\hline 5 & La Fossa & España & TV3 & $\begin{array}{l}\text { Miniserie / } \\
\text { Thriller }\end{array}$ & 4 & $\begin{array}{l}\text { Prime } \\
\text { time }\end{array}$ & 205.000 & 2,8 & 9,20 \\
\hline 6 & \begin{tabular}{|l|} 
A Ley de \\
Santos \\
\end{tabular} & España & TVG & Serie / Thriller & 7 & $\begin{array}{l}\text { Prime } \\
\text { time }\end{array}$ & 89.000 & 3,4 & 10,1 \\
\hline 7 & Serramoura & España & TVG & Serie / Thriller & 18 & $\begin{array}{l}\text { Prime } \\
\text { time }\end{array}$ & 87.000 & 3,3 & 10,0 \\
\hline 8 & \begin{tabular}{|l|} 
O Sabor das \\
Margaridas
\end{tabular} & España & TVG & Serie / Thriller & 6 & $\begin{array}{l}\text { Prime } \\
\text { time }\end{array}$ & 74.000 & 2,8 & 8,3 \\
\hline 9 & \begin{tabular}{|l|} 
El Último \\
Show \\
\end{tabular} & España & $\begin{array}{l}\text { AragónT } \\
\text { V }\end{array}$ & Serie / Drama & 8 & $\begin{array}{l}\text { Prime } \\
\text { time }\end{array}$ & 71.000 & 5,6 & 12,9 \\
\hline 10 & Auga Seca & $\begin{array}{l}\text { España- } \\
\text { Portugal }\end{array}$ & $\begin{array}{l}\text { TVG- } \\
\text { RTP } \\
\end{array}$ & Serie / Thriller & 6 & $\begin{array}{l}\text { Prime } \\
\text { time }\end{array}$ & 70.000 & 2,7 & 8,1 \\
\hline
\end{tabular}

Fuente: Obitel España.

\section{Monitoreo VoD 2020}

El confinamiento domiciliario produjo un aumento significativo del consumo de las plataformas de VoD, que han continuado creciendo y ampliando su propuesta de contenidos, con una oferta cada vez más tematizada, que pone de manifiesto la madurez de la producción de ficción televisiva española. Los estrenos de 2020 incluyen algunos grandes hits internacionales (Élite, Las Chicas del Cable) y ratifican la relevancia del thriller. E1 79,1\% de la ficción VoD autóctona ha debutado este año por primera vez.

\subsection{Mercado de plataformas de VoD}

La oferta de plataformas digitales ha continuado aumentando a lo largo de 2020, así como su demanda (Cuadro 3). Disney+ ha sido 
sin duda el lanzamiento más esperado de año, con una oferta de más de 400 películas y cerca de 7.500 episodios televisivos al precio de 6,99 euros al mes o de 69,99 euros al año. En medio del confinamiento también llegó a España Quibi, la plataforma de contenidos cortos solo para móviles. Sin embargo, solo seis meses después, confirmaba su cierre. Durante el verano, Sky España anunciaba asimismo su clausura, poniendo fin a una aventura que comenzó en 2017. Finalmente, en octubre desembarcó Pluto TV, de ViacomCBS, la primera AVoD (Advertising-Based Video on Demand) del mercado español. Este nuevo servicio de streaming, gratuito y sin registro, cuenta con más de 40 canales temáticos exclusivos y combina televisión lineal y a la carta.

Las plataformas ya consolidadas en nuestro país también han aprovechado 2020 para mejorar su posicionamiento ante la competencia. Orange TV unió fuerzas con AMC Networks International para incrementar su oferta de contenidos y estrenar AMC Selekt, un nuevo servicio bajo demanda sin coste adicional. Netflix comenzó a ofrecer, de forma gratuita, algunos de sus títulos; mientras que Amazon Prime Video estrenó Prime Video Channels, un nuevo servicio que permite añadir canales en streaming sin compromiso de permanencia. Las suscripciones disponibles incluyen Starzplay, MGM y Noggin, entre otros, con precios que oscilan entre los 2,99 y los 9,99 euros al mes.

En cuanto a la demanda de este tipo de servicios, diferentes consultoras se han lanzado a analizar el fenómeno a falta de datos oficiales suministrados por las propias empresas. Según el estudio "OTT y plataformas de pago en España", de Barlovento Comunicación11, Netflix es la OTT que cuenta con una con mayor penetración (33\% de los hogares), seguida de Amazon Prime Video (14,3\%) y HBO (9,4\%). Los resultados de la sexta oleada del Barómetro OTT del Gabinete de Estudios de la Comunicación Audiovisual (GECA) ${ }^{12}$

$11 \mathrm{https} / /$ www.expansion.com/economia-digital/companias/2020/10/30/5f96c807e 5fdea 28548b4594.html

12 https://www.atresmediacorporacion.com/documents/2021/02/25/ACCF96A3-20884208-8394-DD4B4DCEB6D7/atresmediaresultados_2020cnmv.pdf 
corroboran este ranking: Netflix sigue siendo la plataforma más contratada por los usuarios españoles (67,3\% de los encuestados), seguida de Amazon Prime Video (62,1\%) y HBO España (27,3\%). Por el contrario, el estudio de Digital TV Research ${ }^{13}$ señala que Amazon Prime Video y Disney+, con 1,25 millones de suscriptores cada una, comparten la segunda posición, solo por debajo de Netflix (4,2 millones de suscriptores), pero por encima de HBO (731.000). Ahora bien, los únicos datos oficiales son los de las OTT de cadenas nacionales, con 452.000 abonados a Atresplayer Premium ${ }^{14}$ y 109.000 a Mitele Plus a 31 de diciembre de $2020 .{ }^{15}$

\subsection{Análisis del VoD en 2020: la ficción de estreno nacional e ibe- roamericana}

El crecimiento espectacular del VoD en el año del COVID se traduce en los 90 títulos estrenados en la modalidad de VoD (68 en 2019), 40 españoles, 47 iberoamericanos y tres coproducciones. Inés del Alma Mía es una serie hispano-chilena basada en la homónima novela de Isabel Allende sobre la vida de la primera mujer española que llegó a Chile, Inés Suárez. Dime Quién Soy es otra adaptación literaria, en este caso del bestseller del mismo nombre de Julia Navarro, producida por DLO Producciones para Movistar+ y Telemundo. La tercera coproducción, el thriller hispano-estadounidense The Head, ha sido realizada por Mediapro para Hulu Japón y HBO Asia y estrenada en Orange TV.

$13 \mathrm{https}: /$ www.expansion.com/economia-digital/companias/2020/10/30/5f96c807e5fdea 28548b4594.html

$14 \mathrm{https} / /$ www.atresmediacorporacion.com/documents/2021/02/25/ACCF96A3-20884208-8394-DD4B4DCEB6D7/atresmediaresultados_2020cnmv.pdf

15 https://files.mediaset.es/file/10002/2021/02/24/FY_20_SPANISH_CNMV_f7a7.pdf 
Tabla 6. Ficciones nacionales e iberoamericanas exhibidas en 2020 en sistemas de VoD

\begin{tabular}{|c|c|c|}
\hline $\begin{array}{l}\text { TÍTULOS NACIONALES DE } \\
\text { ESTRENO }\end{array}$ & $\begin{array}{l}\text { TÍTULOS } \\
\text { IBEROAMERICANOS } \\
\text { DE ESTRENO }\end{array}$ & COPRODUCCIONES \\
\hline $\begin{array}{l}\text { Netflix - No } 8 \text { nacionales } \\
\text { 1. Alguien Tiene que Morir } \\
\text { (miniserie) } \\
\text { 2. El Desorden que Dejas } \\
\text { (serie) } \\
\text { 3. Élite (serie) } \\
\text { 4. Las Chicas del Cable } \\
\text { (serie) } \\
\text { 5. Los Favoritos de Midas } \\
\text { (serie) } \\
\text { 6. El Sabor de las } \\
\text { Margaritas (serie) } \\
\text { 7. Valeria (serie) } \\
\text { 8. Vivir sin Permiso (serie) } \\
\text { Movistar+- No 10 } \\
\text { nacionales } \\
\text { 19. Benidorm (serie) } \\
\text { 20. By Ana Millán (serie) } \\
\text { 21. Física o Química. El } \\
\text { Reencuentro (miniserie) } \\
\text { 22. La Valla (serie) } \\
\text { 23. \#Luimelia (serie) } \\
\text { 24. Mentiras (serie) } \\
\text { 25. Perdida (serie) } \\
\text { 26. Veneno (serie) } \\
\text { Amazon Prime Video - } \\
\text { No } 9 \\
\text { 27. Caronte (serie) } \\
\text { 28. Desaparecidos } \\
\text { 29. El Cid (serie) } \\
\text { 30. La que Se Avecina } \\
\text { (serie) } \\
\text { 31. Madres (serie) } \\
\text { 32. Relatos Confinados } \\
\text { (serie) }\end{array}$ & $\begin{array}{l}\text { Netflix - No títulos iberoame- } \\
\text { ricanos } \\
\text { 1. Bolivar (telenovela - Méxi- } \\
\text { co) } \\
\text { 2. Casi Feliz (serie - Argentina) } \\
\text { 3. Coisa Mais Linda (serie } \\
\text {-Brasil) } \\
\text { 4. Desenfrenadas (serie - } \\
\text { México) } \\
\text { 5. Diablero (serie - México) } \\
\text { 6. El Dragón (telenovela - } \\
\text { México) } \\
\text { 7. Enemigo Íntimo (telenovela } \\
\text { - EEUU) } \\
\text { 8. Falsa Identidad (telenovela } \\
\text { - EEUU) } \\
\text { 9. La Casa de las Flores (serie } \\
\text { - México) } \\
\text { 10. La Reina del Flow } \\
\text { (telenovela - Colombia) } \\
\text { 11. Monarca (serie - México) } \\
\text { 12. Narcos México (serie - } \\
\text { México) } \\
\text { 13. Omnisciente (miniserie - } \\
\text { Brasil) } \\
\text { 14. Oscuro Deseo (serie - } \\
\text { México) } \\
\text { 15. 3\% (serie - Brasil) } \\
\text { 16. 100 Días para } \\
\text { Enamorarnos (telenovela - } \\
\text { EEUU) } \\
\text { 17. Amar y Vivir (telenovela - } \\
\text { Colombia) } \\
\text { 18. Boca a Boca (serie - Brasil) } \\
\text { 19. Buenos Días Verónica } \\
\text { (serie - Brasil) } \\
\text { 20. Control Z (serie - México) } \\
\text { 21. El Reto del Beso (serie - } \\
\text { Brasil) }\end{array}$ & $\begin{array}{l}\text { Amazon Prime } \\
\text { Vídeo - N } \mathbf{N}^{\circ} \\
\text { 1. Inés del Alma Mía } \\
\text { (serie - España y } \\
\text { Chile) } \\
\text { Movistar+ - No } \mathbf{2} \\
\text { 2. Dime Quién Soy } \\
\text { (serie - España y } \\
\text { Estados Unidos) } \\
\text { Orange TV - No } 1 \\
\text { 3. The Head (serie } \\
\text { - España y Estados } \\
\text { Unidos) }\end{array}$ \\
\hline
\end{tabular}




\begin{tabular}{|c|c|c|}
\hline $\begin{array}{l}\text { TÍTULOS NACIONALES DE } \\
\text { ESTRENO }\end{array}$ & $\begin{array}{l}\text { TÍTULOS } \\
\text { IBEROAMERICANOS } \\
\text { DE ESTRENO }\end{array}$ & COPRODUCCIONES \\
\hline $\begin{array}{l}\text { 33. Señoras del Hampa } \\
\text { (serie) } \\
\text { HBO - } \mathbf{N}^{\circ} \mathbf{3} \\
\text { 34. } 30 \text { Monedas (serie) } \\
\text { 35. En Casa (Antología) } \\
\text { 36. Patria (serie) } \\
\text { Orange } \mathbf{T V}-\mathbf{N}^{\circ} \mathbf{2} \\
\text { 37. Caminantes (serie) } \\
\text { 38. Kosta. The Paradise } \\
\text { (serie) } \\
\text { FOX ESPAÑ - } \mathbf{N}^{\mathbf{0}} \mathbf{1} \\
\text { 39. Vis a Vis. El Oasis (serie) } \\
\text { TNE - } \mathbf{N}^{\mathbf{0}} \mathbf{1} \\
\text { 40. Vamos Juan (serie }\end{array}$ & $\begin{array}{l}\text { 22. El Robo del Siglo } \\
\text { (serie - Colombia) } \\
\text { 23. Espectors (serie -Brasil) } \\
\text { 24. Historia de Un Crimen } \\
\text { (serie - México) } \\
\text { 25. Homemade } \\
\text { (serie - Chile - Italia) } \\
\text { 26. Kissing Game } \\
\text { (serie - Brasil) } \\
\text { 27. La Venganza de Analia } \\
\text { (telenovela - Colombia) } \\
\text { 28. No Te Puedes Esconder } \\
\text { (serie - EEUU) } \\
\text { 29. Puerta } 7 \text { (serie - Argentina) } \\
\text { 30. Reality Z (serie - Brasil) } \\
\text { 31. Secreto Bien Guardado } \\
\text { (serie - Argentina) } \\
\text { 32. Selena (serie) } \\
\text { 33. Siempre Bruja } \\
\text { (serie - Colombia) } \\
\text { 34. The Great Heist } \\
\text { (serie - Colombia) } \\
\text { 35. The Queen And the } \\
\text { Conqueror } \\
\text { (telenovela - Colombia) } \\
\text { 36. The Unremarcable } \\
\text { Juanquini (serie - Colombia) } \\
\text { 37. Chichipatos } \\
\text { (serie - Colombia) } \\
\text { AMAZON PRIME VÍDEO } \\
\text { - 7 títulos } \\
\text { 38. Cómo Sobrevivir Soltero } \\
\text { (serie - México) } \\
\text { 39. De Brutas Nada } \\
\text { (serie - Brasil) } \\
\text { 40. El Candidato } \\
\text { (serie - México) } \\
\text { 41. El Presidente } \\
\text { (serie - Chile - Argentina) } \\
\text { 42. La Jaurí (serie - Chile) } \\
\text { 43. Pan y Circo (serie - México) }\end{array}$ & \\
\hline
\end{tabular}




\begin{tabular}{|l|l|l|}
\hline $\begin{array}{l}\text { TÍTULOS NACIONALES DE } \\
\text { ESTRENO }\end{array}$ & $\begin{array}{l}\text { TÍTULOS } \\
\text { IBEROAMERICANOS } \\
\text { DE ESTRENO }\end{array}$ & COPRODUCCIONES \\
\hline & $\begin{array}{l}\text { FOX - 3 títulos } \\
\text { iberoamericanos } \\
\text { 44. El General Naranjo (serie - } \\
\text { Colombia) } \\
\text { 45. Llámame Bruna (serie - } \\
\text { Brasil) } \\
\text { 46. Aqui en la Tierra (serie - } \\
\text { México) }\end{array}$ & \\
& $\begin{array}{l}\text { HBO - } \\
47 . \text { Dignidad (serie - Chile) }\end{array}$ & \\
\hline Total: 40 & Total: 47 & Total: 3 \\
\hline TOTAL GENERAL: 90 & & \\
\hline
\end{tabular}

Fuente: Obitel España

México recupera la primacía de las aportaciones iberoamericanas con 13 títulos (10 en 2019), seguida de cerca por Colombia (11 títulos) y Brasil (10 títulos). Los tres estrenos argentinos representan dos menos que en 2019.

Tabla 7. La ficción de estreno en 2020 en VOD: países de origen

\begin{tabular}{|l|r|r|}
\hline \multicolumn{1}{|c|}{ País } & \multicolumn{1}{c|}{ Títulos } & \multicolumn{1}{c|}{$\%$} \\
\hline Argentina & 3 & 3,3 \\
\hline Brasil & 10 & 11,1 \\
\hline Chile & 3 & 3,3 \\
\hline Colombia & 11 & 12,2 \\
\hline Ecuador & 0 & 0,0 \\
\hline España & 40 & 44,4 \\
\hline EEUU (producción hispánica) & 5 & 5,6 \\
\hline México & 13 & 14,4 \\
\hline Perú & 0 & 0,0 \\
\hline Portugal & 0 & 0,0 \\
\hline Uruguay & 0 & 0,0 \\
\hline Venezuela & 0 & 0,0 \\
\hline COPRODUCIONES (total) & $\mathbf{5}$ & $\mathbf{5 , 6}$ \\
\hline Coproducciones españolas & $\mathbf{3}$ & 3,3 \\
\hline Coproducciones entre países & $\mathbf{2}$ & 2,2 \\
Obitel & $\mathbf{9 0}$ & $\mathbf{1 0 0 , 0}$ \\
\hline TOTAL GENERAL & & \\
\hline
\end{tabular}

Fuente: Obitel España 
La serie es el formato dominante, con una secuenciación en episodios -generalmente de estructura capitular- que oscila entre los 6 y los 18 y una duración media de 30 minutos aproximadamente para las comedias, y entre 45 y 60 minutos para el resto de las producciones.

Tabla 8. Formatos de la ficción nacional e iberoamericana en VOD

\begin{tabular}{|l|r|r|r|r|r|r|r|r|}
\hline \multirow{2}{*}{ Formato } & \multicolumn{4}{|c|}{ Nacionales } & \multicolumn{4}{c|}{ Ibero-americanos } \\
\cline { 2 - 10 } & Títulos & $\mathbf{\%}$ & $\mathbf{C} / \mathbf{E}$ & $\mathbf{\%}$ & Títulos & $\mathbf{\%}$ & $\mathbf{C} / \mathbf{E}$ & \multicolumn{1}{c|}{} \\
\hline Telenovela & 0 & 0,0 & 0 & 0,0 & 9 & 19,1 & 573 & 63,4 \\
\hline Serie & 40 & 93,0 & 315 & 97,2 & 38 & 80,9 & 331 & 36,6 \\
\hline Miniserie & 2 & 4,7 & 4 & 1,2 & 0 & 0,0 & 0 & 0,0 \\
\hline Telefilme & 0 & 0,0 & 0 & 0,0 & 0 & 0,0 & 0 & 0,0 \\
\hline Unitario & 0 & 0,0 & 0 & 0,0 & 0 & 0,0 & 0 & 0,0 \\
\hline Antología & 1 & 2,3 & 5 & 1,5 & 0 & 0,0 & 0 & 0,0 \\
\hline Otros (soap opera, etc) & 0 & 0,0 & 0 & 0,0 & 0 & 0,0 & 0 & 0,0 \\
\hline Total & $\mathbf{4 3}$ & $\mathbf{1 0 0 , 0}$ & $\mathbf{3 2 4}$ & $\mathbf{1 0 0 , 0}$ & $\mathbf{4 7}$ & $\mathbf{1 0 0 , 0}$ & $\mathbf{9 0 4}$ & $\mathbf{1 0 0 , 0}$ \\
\hline
\end{tabular}

Fuente: Obitel España

\section{Ficción y participación de las audiencias en entornos digitales}

Las ficciones en abierto y plataformas VoD han concentrado su expansión transmedia principalmente en las redes sociales y en los nuevos formatos sonoros. Entre sus estrategias destaca "lavalla2045. com", el microsite de La Valla que, además de los apartados clásicos (personajes, mejores momentos, etc.), incluye contenido exclusivo: una radio clandestina; una recopilación de vídeos de móvil sobre el mundo distópico de la serie y una cartilla de racionamiento, cuyos cupones ofrecen acceso a material complementario. Al igual que \#Luimelia, esta serie también aprovecha las redes sociales para viralizar sus contenidos mediante la creación de stickers. 
Las ficciones de estreno continúan inspirando programas especiales de debate (Mas de Veneno: El Documental o Patria: Detrás de la Serie) o sobre los temas que aborda (Hit y ¿Quién educa a quién?). Patria y La Línea Invisible, dos ficciones centradas en ETA, también cuentan con podcasts de corte documental, mientras que otros universos muy conocidos por la audiencia (La Que Se Avecina, Vis a Vis y Acacias 38) se expanden como ficciones sonoras.

Las producciones de referencia en su expansión transmedia tampoco han dejado de innovar. Dos semanas antes del estreno de su cuarta temporada, El Ministerio del Tiempo lanzaba la precuela de 10 minutos "Antes de que no haya tiempo", que tiende un puente entre las dos últimas temporadas. Skam España celebró una fiesta "en directo" para promocionar el episodio "El concierto" y, aunque los clips de dicho episodio ya estaban grabados, la fiesta se reprodujo al detalle para hacer las actualizaciones en redes sociales en directo e invitar a una veintena de fans. La iniciativa consiguió que el hashtag \#SkamEspaña fuera primera tendencia en Twitter España, y entró entre las tendencias principales de Chile, México y Perú. ${ }^{16}$

\section{\#Luimelia, transmedia y audiencia social}

La pareja formada por Luisita y Amelia, del serial Amar ES Para Siempre, goza de una gran popularidad en las redes sociales y ha acabado convirtiéndose en un fenómeno viral. El volumen de tuits se incrementó en más de un $1.000 \%$ entre la sexta (2017-2018) y la séptima temporada (2018-2019), a media que la audiencia aumentaba el shippeo (término con el que los fans denominan la relación entre ambos personajes femeninos), catapultando la serie desde la posición 36 (T6) a la 2 (T7) del ranking de Social TV ${ }^{17}$. El entusiasmo suscitado

16 Noticia de https://fueradeseries.com/skam-espana-transmedia-fiesta-del-sabado-endirecto-b0e57d39c169

17 Noticia de https://diagonaltv.es/noticia/arranca-la-segunda-y-tercera-temporada-deluimelia/ 
por el serial indujo a Atresmedia a convertir esta historia de amor en un universo independiente. Así nació \#Luimelia (con hashtag como guiño a los fans y al entorno digital en el que nació la producción), la ficción de Atresplayer Premium que traslada a Luisita y Amelia de 1977 (año de ambientación original de su relación en Amar Es Para Siempre) a 2020.

Con el objetivo de que los fans puedan disfrutar y conectar al máximo con la ficción, \#Luimelia completa la experiencia combinando la emisión de los capítulos con las redes sociales de ambos personajes femeninos. En sus perfiles de Twitter e Instagram, la popular pareja publica contenido inédito de su vida cotidiana, opinan sobre la actualidad, interactúan entre ellas, con otros personajes de la serie y con sus seguidores, que las sienten tan próximas como si fueran personas de verdad. A finales de 2020, las cuentas de las protagonistas ya sumaban más de 16.000 seguidores.

Las dos temporadas estrenadas durante 2020 fueron éxitos de audiencia en las redes sociales. En diciembre, \#Luimelia superaba los 718.000 tuits y acumulaba más de 180 millones de impresiones reales y 42 trending topics nacionales. Además, todos los capítulos de la primera temporada se situaron en el top 10 del ranking de lo más comentado de todas las televisiones y plataformas, mientras que los de la segunda temporada aumentaron su visibilidad y figuran entre las tres primeras posiciones. ${ }^{18}$

\section{Lo más destacado de año}

El carácter didáctico de las ficciones de La1 se evidencia en todos sus formatos, con apuestas tan innovadoras y arriesgadas como algunos estrenos de la VoD. La teen serie HIT (1.490.000 espectadores y $9,1 \%$ ) retrata los comportamientos extremos de un grupo de una vez más por las ficciones de TV3, entre las que destaca el $d r a-$

18 Noticia de https://premium.atresplayer.com/luimelia/noticias/estreno-tercera-temporada-proximo-mes-enero_202012115fd3828559ccfa000179d602.html 
medy juvenil Drama (280.000 espectadores y 11,5\% de share), una serie bilingüe emitida también por Playz y YouTube, que ha desatado una encendida polémica en las redes sociales sobre el uso combinado del catalán y del castellano. La Fossa (205.000 espectadores y 9,2 de share), otra de las novedades de la cadena catalana, es un thriller con ritmo pausado y look cinematográfico protagonizado, como Néboa, por una mujer policía. Al igual que el thriller de TVG El Sabor de las Margaritas (74.000 espectadores y 8,3\%), cuya primera temporada se convirtió en la ficción de habla no inglesa más vista de Netflix en Reino Unido e Irlanda durante el pasado mes de abril. ${ }^{19}$

Los 44 estrenos de la ficción VoD de 2020 ofrecen un amplio abanico de géneros y de temáticas que reflejan la diversidad, la versatilidad y la elevada calidad media de la producción española de ficción. Una vez más, Movistar+ es la plataforma con el mayor número de títulos (10) en un año extremadamente competitivo. El policiaco Antidisturbios ha sido la serie más vista de la plataforma de Telefónica y una de las mejor valoradas, con una audiencia sostenida superior al $80 \%$ (nueve de cada diez personas que han comenzado a verla la han terminado $)^{20}$. Le sigue La Línea Invisible, sobre la fundación de ETA y los primeros asesinatos cometidos por la banda armada, y La Unidad, un policiaco sofisticado de factura impecable, ambientado en la lucha contra el terrorismo yihadista. La mirada retrospectiva sobre ETA es también el objetivo de Patria, una adaptación de la homónima novela de Fernando Aramburu que comparte protagonismo en HBO con 30 Monedas, el thriller de terror con elementos paranormales del cineasta Álex de la Iglesia.

Atresplayer incluye entre sus ficciones más populares dos reivindicaciones de la diversidad de género: la ya citada \#Luimelia y Veneno, el biopic de una transexual devorada por la televisión exhibi-

19 https://www.farodevigo.es/sociedad/2019/05/11/sabor-margaritas-triunfa-reino-unido-15697207.html

$20 \mathrm{https}$ //comunicacion.movistarplus.es/email/antidisturbios-ya-es-la-serie-mas-vistaen-movistar-este-2020/ 
cionista de los late shows nocturnos de los noventa. Esta última serie, reemitida por Antena3 en octubre, obtuvo una media de 2.424.000 espectadores (16,9\% de share), 2,5 puntos por encima de la ficción más vista del año, Cuéntame Cómo Pasó, que la sitúan en el puesto número 18 de los programas con más audiencia. Por el contrario, la redifusión en Tele5 de su comedia La que Se Avecina, tras el estreno de su duodécima temporada en Amazon Prime Vídeo, no ha corrido la misma suerte (1.536.000 espectadores y $9,2 \%$ de share).

Además de las cinco ficciones de Tele5 emitidas en Amazon Prime Video, el grupo Mediaset también cuenta este año con otras dos series de estreno en HBO y Netflix respectivamente: la ya citada $\mathrm{Pa}$ tria y la segunda temporada de Vivir sin Permiso, que en esta ocasión ha privilegiado el drama sobre el thriller.

La tercera temporada de Élite constituye la apuesta de Netflix por las teen series, con este drama juvenil convertido en una de las ficciones más vistas de la plataforma norteamericana a nivel mundial. Netflix también incluye entre sus ocho estrenos de 2020 la quinta y última temporada de Las Chicas del Cable y la adaptación del thriller de Carlos Montero El Desorden que Dejas, del que también es director y guionista. Finalmente, cabe destacar el debut de OrangeTV española con tres thrillers: Caminantes, la ya citada The Head y la coproducción con Finlandia Kosta. The Paradise.

\section{Tema del año. La Ficción en tiempos de pandemia en España}

El primer año de la pandemia paralizó la industria audiovisual. Se aplazaron todos los rodajes de televisión, incluidos los de la ficción nacional, que a mediados de marzo bordeaban la treintena ${ }^{21}$. Otras tareas de la cadena de producción también se vieron afectadas, 
aunque gracias a la tecnología se fueron adaptando a la escritura virtual de guiones, al igual que los procesos de pre y postproducción.

Lo más destacado del año provino de la misma industria televisiva, que trató de convertir la necesidad impuesta en oportunidad creativa. Así, se dispuso a reflexionar sobre el confinamiento a partir de la realización de ficciones en unas condiciones excepcionales, las que permitían el interior de los hogares. Una respuesta que aspiraba a remediar la carencia -y el retraso- de estrenos en pleno aislamiento social por el Coronavirus, además de aportar una representación audiovisual constructiva de esa experiencia inédita que estábamos descubriendo. El confinamiento y el COVID-19 surgieron de manera instantánea como temas de inspiración para crear ficción televisiva. Canales públicos y plataformas VoD produjeron y emitieron ficciones cuyo contenido versaba y mostraba la realidad de la crisis.

Las primeras iniciativas procedieron de las cadenas públicas. TV3 estrenó el uno de abril Jo També Em Quedo a Casa, una tragicomedia diaria de 20 episodios, producida por Yumagic, escrita por Blanca Bardagil y Sergi Cervera, y dirigida por este último. Plantea la separación sentimental de una pareja que se ve obligada a convivir debido al confinamiento. Se trata de una propuesta breve, de 15 minutos por capítulo y técnicamente austera, que emplea planos fijos estándar en las interacciones entre personajes insertadas mediante supuestas videollamadas y redes sociales. El rodaje se efectuó en pocos días, con dos técnicos que se desplazaban a las casas de los actores y grababan con un set elemental: micro, cámara y un par de focos.

Una semana después TVE estrenaba, en horario de máxima audiencia, Diarios de Cuarentena, iniciativa de Morena Films, escrita y dirigida por Álvaro Fernández-Armero y David Marqués. Se presentaba en formato de sitcom, con ocho episodios de 30 minutos cada uno en continuidad, a partir de tramas entrelazadas que narraban distintas experiencias cotidianas vividas en los hogares confinados. El relato costumbrista buscaba reflejar la actualidad mediante el humor, 
amenizando a la audiencia y empatizando con ella a través de situaciones cómicas de la reclusión. Estaba ambientada en una decena de casas e interpretada por actores, parejas y convivientes, que también se encargaron del rodaje, decorado, vestuario y maquillaje. A pesar de la modesta audiencia cosechada (8,4\% share), TVE anunció la venta del formato para su adaptación en Francia y México. ${ }^{22}$

Las plataformas VoD optaron por encargar trabajos a distintos cineastas para conformar series antológicas, cuyo tema común versara sobre la pandemia o el confinamiento. HBO España recurrió a cineastas jóvenes -Leticia Dolera, Rodrigo Sorogoyen, Paula Ortiz, Carlos Marques-Marcet, Elena Martín- para componer En Casa, miniserie integrada por cinco mediometrajes de 15 a 40 minutos cada uno, que abordan, mediante diferentes géneros, la mirada particular de los realizadores desde y sobre el encierro. En términos generales, se atisba una colección autoral, donde las relaciones personales conforman el denominador común que entrelaza la disparidad de las historias. A pesar de las limitaciones del enclaustramiento, la producción de la serie se realizó en un tiempo récord, tan sólo transcurrieron dos meses entre el anuncio del proyecto (14 de abril) y su estreno (3 de junio).

Un mes después, Amazon Prime Video se sumó con una compilación similar: Relatos Con-fin-a-dos, una creación de Álvaro Longoria y Cecilia Gessa rodada asimismo durante el encierro por una docena de actores en sus hogares. Sus cinco episodios autoconclusivos, de 20 minutos cada uno, estaban dirigidos por Fernando Colomo, Miguel Bardem, Juan Diego Botto y los creadores de Diarios de Cuarentena: Álvaro Sánchez-Armero y David Marqués. En este caso, las narraciones comparten la temática del aislamiento desde planteamientos singulares, con inesperados giros de guion. 
Las series originales de las plataformas presentaban relatos personales, asimétricos y artísticos. Las historias narradas extendían la representación del confinamiento, ampliaban la pluralidad de la memoria colectiva y complementaban, mediante propuestas más experimentales, los relatos ofertados por los canales públicos, que se servían de historias y situaciones más cotidianas. Se trataba de cumplir con una misión de carácter emocional, que evidenciaba la identificación con el público a través del humor, la empatía y algunos ejemplos de colectividad, contacto y colaboración entre personas.

Con estas proposiciones, la industria ha acreditado iniciativa, avidez creativa, dinamismo y capacidad de adaptación a las circunstancias. También se constata cierta precarización estética -homogenización de recursos, planos, decorados- y simplificación narrativa debido a la carencia de tiempo, medios y profesionales técnicos. En cualquier caso, las diferentes aportaciones integran una ficción testimonial de la pandemia que ha funcionado como una crónica poliédrica y diversa, ejecutada durante la primera ola de contagios cuando imperaban las máximas restricciones a la movilidad, con las dificultades que ello contraía: crear y planificar con celeridad, sortear las dificultades técnicas y expresar con un menor ritmo narrativo.

En la coyuntura del encierro, el modelo de trabajo adoptó una forma análoga. Cada hogar de actores recibía un teléfono, un micrófono y un trípode para grabar sus escenas. El elenco artístico sumaba a las labores interpretativas otras técnicas -desde operador de cámara a maquillador- con recursos limitados. Después enviaban el material grabado a los montadores y directores -que previamente habían ensayado y proporcionado indicaciones técnicas al reparto por videollamada- mientras que los guionistas escribían a contrarreloj.

Más allá de los títulos citados, el resto de las ficciones se resistieron a incorporar la pandemia en sus universos narrativos. Agregar el virus en las nuevas tramas suponía el riesgo de normalizarlo y conllevaba cambiar el tono y la estética de los proyectos, además de 
perder la expresión de los intérpretes bajo las mascarillas. De hecho, la única producción en donde se inoculó el coronavirus fue Cuéntame Cómo Pasó. Los guionistas propusieron para la 21 temporada (que comenzará el 14 de enero de 2021) un salto temporal de 1992 a 2020, para mostrar la incidencia de la pandemia, que sitúa a la hija menor de los Alcántara combatiendo al virus en primera línea como doctora mientras que el hijo escritor cuida de sus padres. La alteración temporal y su conexión con el presente se justifica al valorar la pandemia como un acontecimiento tan extraordinario que consigue ocupar un lugar privilegiado en el álbum de los momentos históricos del país representados a modo de espejo en la serie.

En cuanto a la distribución de la ficción en streaming en canales gratuitos, merece reseñarse la coproducción española-australiana Cancelled (Screen Australia), que narra la historia de sus protagonistas -la actriz María Albiñana y el director de cine Luke Eve- quienes tuvieron que cancelar a última hora su boda por el Coronavirus y confinarse con la madre de él, en Valencia. Un relato naturalista, a medio camino entre la comedia y el drama, articulado en 10 capítulos, cada uno de 9 minutos de duración, que se estrenó en Facebook, pasó a la plataforma $V I X$-donde logró dos millones de visualizaciones en 48 países- y ganó varios premios internacionales, como el de mejor serie de 2020 en los British Web Awards. ${ }^{23}$

Ante la parálisis global y la incertidumbre que generaba la evolución de la epidemia, la reactivación de la producción de ficción televisiva no se alcanzó hasta finales del mes de mayo, en la fase 1 de la desescalada. Las producciones retomaron entonces los rodajes, de forma escalonada, aunque condicionados por los protocolos requeridos por el Ministerio de Sanidad y elaborados por, entre otras, la Agrupación de Asociaciones del Audiovisual $(A A A)$ o la Asociación de Directores de Ficción de Televisión (Dirige), con el fin de evitar 
riesgos laborales y nuevos contagios. Entre las medidas destacaban: limitación de 25 personas en el aforo del set, realización de pruebas PCR, tomas de temperatura, ampliación de espacios para mantener la distancia de seguridad, casting telemático o equipos de desinfección de zonas, material y vestuario. Se calcula que las medidas incrementaron el coste de la producción entre el 2 y el $10 \%$ del presupuesto. ${ }^{24}$

La ola de la pandemia también alcanzó a los guiones. Por ejemplo, en los seriales con ritmos intensos de grabación (Mercado Central, Amar Es Para Siempre y Acacias 38) se reescribieron los libretos para adaptarlos a las nuevas necesidades de rodaje, reducir el número de figurantes, retrasar determinadas tramas o eludir secuencias con contacto físico ${ }^{25}$. Algunas de las nuevas escenas se resolvieron con elipsis o grabándose por capas a metro y medio de distancia y después montándose en paralelo para dar la impresión de que los intérpretes estaban juntos cuando en realidad se captaban separados.

La ficción televisiva se erigió como un recurso de entretenimiento esencial y recurrente para el público durante la pandemia. Fue capaz de reinventarse y asumió funciones de representación, contención y desahogo en este momento crítico de la historia reciente.

$24 \mathrm{https://www.elmundo.es/cultura/cine/2020/06/24/5ef2003ffc6c83f8018b45ef.html}$ 25 https://elpais.com/television/2020-05-02/como-devolver-la-normalidad-a-la-television-tras-la-crisis-del-coronavirus.html 